\title{
Correction to: Enrollment in Supplemental Insurance Coverage Among Medicare Beneficiaries by Race/Ethnicity
}

\author{
Sungchul Park ${ }^{1} \cdot$ David J. Meyers $^{2} \cdot$ Maricruz Rivera-Hernandez $^{2}$
}

Published online: 29 November 2021

c) W. Montague Cobb-NMA Health Institute 2021

\section{Correction to: Journal of Racial and Ethnic Health Disparities https://doi.org/10.1007/s40615-021-01138-w}

Figure 2 in this article as originally published included 3 extraneous graphs in addition to the 2 correct graphs.

The original article has been corrected.

Publisher's Note Springer Nature remains neutral with regard to jurisdictional claims in published maps and institutional affiliations.

The original article can be found online at https://doi.org/10.1007/ s40615-021-01138-w.

Sungchul Park

smp462@drexel.edu

1 Department of Health Management and Policy, Dornsife School of Public Health, Drexel University, Philadelphia, PA 19104, USA

2 Department of Health Services, Policy, and Practice, School of Public Health, Brown University, Providence, RI 02912, USA 